\title{
Ética e Projeto de Engenharia: algumas reflexões em torno da formação em Engenharia Civil
}

DOI: 10.37702/2175-957X.COBENGE.2021.3659

Mauricio Leonardo Aguilar Molina - mauricio.aguilar@engenharia.ufjf.br Universidade Federal de Juiz de Fora

Rua Severino Meireles 325

36025-040 - Juiz de Fora - MG

Resumo: $O$ crescimento populacional demanda soluções sustentáveis perante necessidades como energia, água, saneamento e infraestrutura. Por outro lado, o crescimento das atividades extrativistas de alto risco ambiental aumenta o risco de catástrofes em obras como barragens, usinas nucleares, viadutos ou prédios, com custos sociais, ambientais e financeiros. Isso tem suscitado discussões sobre o papel dos engenheiros e as consequências das suas ações. Diferentes instrumentos normativos incorporam a responsabilidade do engenheiro através do conceito de Ética Profissional - o conjunto de princípios ou padrões que pautam a conduta profissional no cotidiano da prática da engenharia. A formação dos engenheiros civis envolve rigor científico e técnico, mas escassa discussão de questões sociais, políticas ou éticas. Os códigos de ética descrevem preceitos que norteiam o exercício da profissão, mas são omissos quanto à definição do próprio conceito ou de qualquer estrutura útil para pensar objetivos de aprendizagem da Ética e da responsabilidade profissional. A Ética vem ganhando importância significativa nos últimos anos. No entanto, isso parece não se refletir na formação dos futuros engenheiros, a partir de uma revisão de uma amostra currículos de cursos de Engenharia Civil no Brasil. Enquanto grande parte deles aborda a Ética e o Projeto através de disciplinas isoladas, poucos tratam esses assuntos de maneira transversal, por meio de abordagens teórico-conceituais. É necessário sensibilizar os futuros engenheiros sobre questões inerentes à atividade profissional através de padrões de conduta que desenvolvam sua capacidade de julgamento perante diversos dilemas éticos-morais que surgem entre objetivos conflitantes, muitas vezes sob grandes pressões financeiras ou políticas.

Palavras-chave: Ética, Projeto de Engenharia, Ensino, Currículo 


\section{ÉTICA E PROJETO DE ENGENHARIA: ALGUMAS REFLEXÕES EM TORNO DA FORMAÇÃO EM ENGENHARIA CIVIL}

\section{INTRODUÇÃO}

A engenharia é uma das profissões mais antigas, juntamente com a medicina e o direito. No entanto, as últimas duas são diferentes pois geralmente estão a serviço de indivíduos ou empresas específicas, enquanto a engenharia tem um escopo mais amplo e, consequentemente, a sua responsabilidade é mais frequentemente com a sociedade do que com pessoas específicas (HABASH, 2018).

Diferentemente dos cientistas, que descobrem o mundo que existe, os engenheiros constroem coisas que servem à sociedade; criam mundos que nunca existiram (CRAWLEY, 2014); criam novas ideias e conceitos, inventam e constroem dispositivos e estruturas e mais que qualquer coisa - os engenheiros resolvem problemas da sociedade, de acordo com a literatura clássica (KRICK, 1970; BAZZO e PEREIRA, 2011).

O ABET Accreditation Board for Engineering \& Technology (WRIGTH, 2002) define a engenharia como "a profissão na qual um conhecimento das ciências matemáticas e naturais adquiridas pelo estudo, experiência e prática é aplicado com critério para desenvolver modos de usar de maneira econômica os recursos e forças da natureza em benefício da humanidade". Para a Canadian Academy of Engineering (CAE, 1999), tratase de "uma profissão preocupada com a criação de sistemas, processos e produtos novos e aprimorados. O foco central da engenharia é o projeto, uma arte que envolve o exercício da engenhosidade, a imaginação, o conhecimento, a habilidade, a disciplina e o julgamento com base na experiência".

Segundo a ASCE - American Society of Civil Engineering (2005), "os engenheiros civis projetam, constroem e mantêm a infraestrutura física da nossa sociedade moderna estradas e pontes, sistemas de água potável e energia, portos e aeroportos marítimos e a infraestrutura para um ambiente mais limpo, para citar apenas alguns".

O Código de Ética e Deontologia da Ordem dos Engenheiros de Portugal caracteriza a engenharia como uma profissão de confiança pública, o que implica que suas soluções devem ser acompanhadas por um compromisso com princípios éticos e deveres deontológicos inerentes ao exercício responsável da profissão (OEP, 2014).

No âmbito normativo, a Lei № 5. 194, de 24 dez 1966 (BRASIL, 1966), caracteriza a profissão do Engenheiro pela realização de um conjunto de atividades de "interesse social e humano", por profissionais com diplomas reconhecidos pelo Estado e fiscalização do Conselho Federal de Engenharia e Agronomia e dos Conselhos Regionais de Engenharia e Agronomia - o sistema CONFEA-CREA, organizados de forma a assegurarem unidade de ação (CONFEA, 1966).

Os domínios da Engenharia em geral e da Engenharia Civil em particular são de grande abrangência e complexidade pelo seu caráter multifacetado. Nesse sentido, as transformações tecnológicas que vêm surgindo projetam mudanças significativos no médio prazo e colocam alguns desafios para o setor. A irrupção de tecnologias como Inteligência Artificial, robotização, drones e veículos autônomos, potencializadas pela Nanotecnologia e a Internet, começam a mudar a forma do mundo que conhecemos. A chamada "Indústria 4. 0" traz um novo contexto que traz desafios inéditos para a Engenharia Civil, onde seus profissionais hoje não são mais apenas usuários de tecnologias fechadas, mas protagonistas no complexo processo de transformação do setor.

$\mathrm{Na}$ vida cotidiana, o trabalho habitual da Engenharia Civil tem como forma visível estruturas ou dispositivos físicos concretos - edifícios, pontes, estradas - e isso acaba 
obscurecendo sua complexidade. Tradicionalmente a formação dos engenheiros tem privilegiado aspectos técnicos e científicos, negligenciando uma formação no âmbito das humanidades. Esse fato fomenta uma convicção de que tais competências não teriam a ver com o âmbito disciplinar do Engenheiro; ou seja, não seria tarefa do Engenheiro se preocupar com questões de corte "humanístico", conforme observa Aravena (2019) ... Por outro lado, é pouco comum nos currículos de cursos de Engenharia Civil disciplinas que tratem da formulação de problemas de projeto de engenharia desde uma perspectiva ampla, como recomendado na literatura tradicional (KRICK, 1970; BAZZO e PEREIRA, 2011). Isso faz com que os engenheiros tendam a lidar essencialmente com os aspectos técnicos dos projetos, sem uma preocupação com sua concepção e desenvolvimento, bem como os desdobramentos das suas ações profissionais, o que pode explicar muitas situações de colapso em obras da Engenharia Civil, como nos casos das barragens de rejeitos Mariana e Brumadinho, ou também, obras públicas cujos resultados parecem ser não ter sido previstos.

\section{O QUE É ÉTICA?}

Ética é um desses termos corriqueiros nem sempre com uma compreensão do seu significado e alcances. De acordo com Nahra (1999), ética (do grego ethos,) é "o conjunto de regras e princípios que devem orientar a ação humana", de onde decorre que a ética na Engenharia é o conjunto de regras e princípios que devem orientar os engenheiros em sua atividade profissional. Já o termo Moral (do latim mos, "caráter", "costumes") tem etimologia similar e, por isso, muitas vezes se confunde com o conceito de Ética na linguagem cotidiana. Ambos estão entrelaçados e se completam, visto que a moral é entendida como um conjunto de normas para a ação, as quais definem o que é ou não aceito como prática; ela é fruto de padrões culturais consensualmente aceitos, datados e situados. A Etica foi fundamental para o desenvolvimento da humanidade ao evitar sua autodestruição pelo uso da força e é composta por um conjunto de princípios pelos quais se pauta a conduta humana, sendo considerada, em um sentido amplo, uma ciência normativa, em contraste com as ciências exatas, pois trata de normas para pautar a conduta humana.

No âmbito da Engenharia, a ética profissional tem implicação direta na responsabilidade do profissional em torno dos efeitos e consequências dos projetos realizados e que dependem do conhecimento e da prática profissional. A aprovação da Lei № 12.846, de 1ำ de agosto de 2013 (BRASIL, 2013), chamada de "Lei Anticorrupção" incorporou um novo termo ao glossário profissional no contexto da construção civil, com estreita ligação com o conceito de ética. De origem anglo-saxã, o termo "compliance" deriva da expressão "to comply" e implica na conformidade com legislação e exigências contratuais. Desse modo, a adoção de práticas de compliance é agenda fundamental das corporações, que devem desenvolver e incorporar códigos e práticas em termos de condutas éticas efetivas.

O Código Brasileiro de Ética para engenheiros descreve princípios, objetivos, atributos, obrigações, proibições e direitos que norteiam o exercício da profissão, abordando os deveres e condutas que são proibidas e qualificando possíveis infrações (CONFEA, 2019). No entanto, ele é omisso quanto à definição do próprio conceito e de qualquer estrutura útil para pensar objetivos de aprendizagem da Ética e da responsabilidade profissional.

\section{A AMBIGUIDADE DO CONCEITO DE PROJETO}

Projeto é um conceito cuja definição envolve algum grau de imprecisão pelo fato de, que, na língua portuguesa, um único termo "projeto" exprime dois sentidos diferentes, que em línguas como o Inglês são expressos por design, que significa concepção ou idealização 
(de um projeto), e project, que exprime a ideia de plano, programa ou empreendimento. Essa imprecisão torna-se mais patente ao olhar as definições legais dadas pelo CONFEA, conforme se aprecia no Anexo I da Resolução № 1.010 de 22 de agosto de 2005 (CONFEA, 2005), onde o termo projeto é definido como a "representação gráfica ou escrita necessária à materialização de uma obra ou instalação, realizada através de princípios técnicos e científicos, visando à consecução de um objetivo ou meta, adequando-se aos recursos disponíveis e às alternativas que conduzem à viabilidade da decisão". Por sua parte, a Decisão Normativa № 1.062 do CONFEA, de 29 de dezembro de 2014 (CONFEA, 2014), conceitua o termo projeto como "a somatória do conjunto de todos os elementos conceituais, técnicos, executivos e operacionais abrangidos pelas áreas de atuação, pelas atividades e pelas atribuições dos profissionais da Engenharia e da Agronomia [... ]".

Percebe-se aqui que as definições do CONFEA, órgão reitor da profissão, tem uma visão do conceito de projeto limitada apenas à representação e à enumeração das atividades de uma obra ou instalação, o que contrasta com a visão do engenheiro como um profissional do projeto (no contexto do design), conforme definido na literatura clássica (KRICK, 1970; BAZZO e PEREIRA, 2011) e também pelas diferentes correntes no âmbito da Filosofia da Engenharia e da Tecnologia abordadas por Aravena (2019). Essa visão limitada dos órgãos oficiais quanto ao papel da Engenharia constitui um empecilho na formação dos engenheiros, cujos atribuições profissionais são definidas justamente pelo sistema CONFEA-CREA.

O surgimento de empreendimentos de crescente complexidade e ordem de grandeza demanda equipes de trabalho multidisciplinares para dar conta de problemas cada vez mais complexos, o que faz com que o papel do projeto de Engenharia vá muito além da simples confecção de planos e especificações finais. Há uma série de objetivos adicionais que devem ser alcançados muito antes de que os desenhos sejam concluídos, ou ainda iniciados. É da responsabilidade do engenheiro conceber projetos e prever e se preocupar com as consequências e o impacto deles, especialmente quando acarretam impactos para a comunidade. Para isso devem ser capazes de prever até os últimos efeitos de uma dada proposta de projeto, tanto como especificar as ações necessárias para que tais resultados sejam alcançados. Portanto, o engenheiro deve estar fortemente comprometido com as necessidades da sociedade, bem como com a aceitação e efeitos de suas obras.

\section{OS DESAFIOS DA DEMANDA POR UMA NOVA ENGENHARIA CIVIL}

O capital humano constitui um dos fatores críticos na produtividade e competitividade para o futuro de um país. Nesse sentido, o Brasil tem enfrentado algumas dificuldades pois, segundo o Índice Global de Inovação, o país retrocedeu 22 posições de 2011 até 2016, situando-se em 69 lugar entre 128 países, o que se manteve até 2017 (CNE/CES, 2019a). Em 2019, o Brasil avançou para a posição 66, de acordo com o mesmo Índice Global de Inovação (Gll, 2019).

Um número importante de atores de diversos setores produtivos do país, os quais, articulados através do movimento Mobilização Empresarial pela Inovação (MEI, 2016), se reuniram para discutir o ensino de Engenharia no Brasil. O objetivo do movimento é a elevação da qualidade do ensino em Engenharia no país, permitindo maior flexibilidade na estruturação dos cursos, de modo a induzir as instituições de ensino a inovar em seus modelos de formação. O resultado esperado dessa iniciativa deverá traduzir-se em uma redução da taxa de evasão nos cursos de Engenharia (ABENGE, 2018), e a consequente formação de "mais e melhores engenheiros" (OLIVEIRA, 2019).

A demanda por "mais e melhores engenheiros" visa a superação do modelo profissional atual, de caráter funcional e orientado principalmente para o trabalho técnico. 
No caso do Engenheiro Civil, seu papel vai além da sua responsabilidade funcional e exige uma visão social e política, em função das demandas atuais de desenvolvimento do país. Nesse contexto, o professor constitui um elemento-chave para que tais demandas e princípios possam passar da reflexão para a ação.

O setor produtivo brasileiro encontra dificuldades para recrutar trabalhadores qualificados para atuar na fronteira do conhecimento das engenharias, destacando a falta de profissionais com habilidades de liderança, trabalho em equipe, concepção de projetos, planejamento, gestão estratégica e aprendizado autônomo - as chamadas "soft skills". Isso traz uma demanda pela modernização dos cursos de Engenharia e sua atualização contínua diante das profundas transformações que estão em andamento no mundo da produção e do trabalho, em especial, com a emergência da manufatura avançada, no contexto da chamada "Indústria 4.0".

Por outro lado, a formação dos engenheiros em geral não privilegia o desenvolvimento de competências no âmbito das Humanidades. Esse fato faz com que seja lugar comum achar que tudo que não for técnico estaria fora das incumbências disciplinares da Engenharia. Noutras palavras, na cultura dominante, considera-se correto pensar que não é tarefa dos engenheiros se preocupar com considerações de ordem filosófica (ARAVENA, 2019). Percebe-se ainda nas normativas do CONFEA a falta de competências entendidas como necessárias para o exercício profissional no mundo globalizado. Essa crítica surge tanto nos setores produtivos quanto em diversos grupos sociais afetados pelo desenvolvimento tecnológico, o que indica que o papel do Engenheiro é relevante não apenas economicamente como também socialmente (ABENGE, 2018). A falta de uma formação humanista dos engenheiros traz como consequência a falta de compreensão do seu papel na formulação de problemas da sociedade e sua resolução, competências essas que constituem a essência da Engenharia, de acordo com a literatura clássica (KRICK, 1970; BAZZO e PEREIRA, 2011).

A promulgação, em 24 de abril de 2019, da Resolução CNE/CES № 2/2019, que instituiu as novas Diretrizes Curriculares Nacionais para cursos de Engenharia (CNE/CES, 2019b), visa dar uma resposta aos desafios.

\section{AS NOVAS DCN}

A Resolução CNE/CES № 2/2019 (CNE/CES, 2019b), que instituiu as novas Diretrizes Curriculares Nacionais para cursos de Engenharia (DCN), recomenda uma formação que garanta o desenvolvimento, pelos futuros engenheiros, de competências para atuação Ética nos moldes da legislação, com atividades que promovam ao longo do curso a integração curricular das dimensões técnicas, científicas, econômicas, sociais, ambientais e éticas. No articulado das novas DCN, Ética e Projeto são competências que destacam como essenciais na definição do perfil do egresso:

\section{"[... ]}

Art. $3^{\circ} \mathrm{O}$ perfil do egresso do curso de graduação em Engenharia deve compreender, entre outras, as seguintes características:

I - Ter visão holística e humanista, ser crítico, reflexivo, criativo, cooperativo e ético e com forte formação técnica;

$[\ldots]$

Art. 4ำ $\mathrm{O}$ curso de graduação em Engenharia deve proporcionar aos seus egressos, ao longo da formação, as seguintes competências gerais:

I - formular e conceber soluções desejáveis de Engenharia, analisando e compreendendo os usuários dessas soluções e seu contexto:

a) ser capaz de utilizar técnicas adequadas de observação, compreensão, registro e análise das necessidades dos usuários e de seus contextos sociais, culturais, legais, ambientais e econômicos; 
b) formular, de maneira ampla e sistêmica, questões de Engenharia, considerando o usuário e seu contexto, concebendo soluções criativas, bem como o uso de técnicas adequadas;

$[\ldots]$

III - conceber, projetar e analisar sistemas, produtos (bens e serviços), componentes ou processos:

a) ser capaz de conceber e projetar soluções criativas, desejáveis e viáveis, técnica e economicamente, nos contextos em que serão aplicadas; b) projetar e determinar os parâmetros construtivos e operacionais para as soluções de Engenharia;

$[\ldots]$

VI - Trabalhar e liderar equipes multidisciplinares:

b) atuar, de forma colaborativa, ética e profissional em equipes multidisciplinares, tanto localmente quanto em rede;

VII - conhecer e aplicar com ética a legislação e os atos normativos no âmbito do exercício da profissão:

a) ser capaz de compreender a legislação, a ética e a responsabilidade profissional e avaliar os impactos das atividades de Engenharia na sociedade e no meio ambiente.

b) atuar sempre respeitando a legislação, e com ética em todas as atividades, zelando para que isto ocorra também no contexto em que estiver atuando;

VIII - o processo de autoavaliação e gestão de aprendizagem do curso que contemple os instrumentos de avaliação das competências desenvolvidas, e respectivos conteúdos, o processo de diagnóstico e a elaboração dos planos de ação para a melhoria da aprendizagem, especificando as responsabilidades e a governança do processo;

$[\ldots]$

$\S 4^{\circ}$ Devem ser implementadas, desde o início do curso, as atividades que promovam a integração e a interdisciplinaridade, de modo coerente com o eixo de desenvolvimento curricular, para integrar as dimensões técnicas, científicas, econômicas, sociais, ambientais e éticas".

Uma revisão em torno da formação em Projeto de Engenharia e Ética foi feita em uma amostra de 28 currículos selecionados na Internet. Na amostra considerada, percebese que o desenvolvimento da competência em Ética tem recebido pouca atenção, o que se reflete no fato de 21 cursos abordá-la em apenas uma disciplina, conforme ilustrado no Quadro 1.

A visão disciplinar estanque do tema começa aos poucos a dar espaço a uma visão mais abrangente, como mostra o currículo do curso de Engenharia Civil da Universidade de São Paulo, no qual o conceito é desenvolvido através de 9 disciplinas, ou na Universidade de São João del Rey, onde é tratado em 4 disciplinas.

Quanto à competência em projeto, em dois cursos - USP-São Paulo e PUC-PR, o conceito é desenvolvido em quatro disciplinas relacionadas, enquanto no restante dos currículos, apenas foram encontradas menções ao termo "projeto" em disciplinas como Introdução à Engenharia, em todos os casos relacionadas à noção do conceito inglês de project.

Este fato sugere que as novas $\mathrm{DCN}$ ainda não têm sido implementadas na maioria dos casos, por um lado, pelo fato de que os três anos de prazo inicialmente definidos para sua entrada em vigor teve uma extensão de mais um ano (até abril de 2023). Por outro lado, é comum a existência de dificuldades internas de caráter político ou, ainda, dificuldades oriundas do fato de as novas DCN terem o caráter de diretrizes; ou seja, não prescreverem qualquer esquema metodológico para sua implementação. 
Quadro 1 - A formação em Ética na Engenharia Civil.

\begin{tabular}{|c|c|c|c|c|}
\hline & Instituição & $\begin{array}{l}\text { Ano do } \\
\text { currículo }\end{array}$ & Disciplinas & $\begin{array}{l}\text { Número de } \\
\text { disciplinas }\end{array}$ \\
\hline 1 & USP-SP & 2018 & Conjunto de 9 disciplinas & 9 \\
\hline 2 & UFSJ & 2017 & $\begin{array}{l}\text { Introdução à Engenharia Civil; Indivíduos, } \\
\text { Grupos e Sociedade Global; Ciência, } \\
\text { Tecnologia e Sociedade; Meio Ambiente e } \\
\text { Gestão para a Sustentabilidade }\end{array}$ & 4 \\
\hline 3 & IFMG & 2018 & $\begin{array}{l}\text { Metodologia Científica; Fenômenos de } \\
\text { Transportes; Humanidades, Ciências Sociais } \\
\text { e Cidadania }\end{array}$ & 3 \\
\hline 4 & UFRJ & ND & Ética 1; Ética do Setor Público & 2 \\
\hline 5 & UFVJM & 2011 & $\begin{array}{l}\text { Introdução às Engenharias; Legislação e } \\
\text { Ética Profissional }\end{array}$ & 2 \\
\hline 6 & UFERSA & 2017 & $\begin{array}{l}\text { Seminário de Introdução ao Curso; Ética e } \\
\text { Legislação }\end{array}$ & 2 \\
\hline 7 & UFSB & 2020 & $\begin{array}{l}\text { Introdução à Engenharia Civil; Introdução à } \\
\text { Administração }\end{array}$ & 2 \\
\hline 8 & ESTÁCIO-Brasília & 2019 & Filosofia, Ética e Cidadania & 1 \\
\hline 9 & IFPE & 2017 & Humanidades & 1 \\
\hline 10 & IFRN & 2019 & Informática Aplicada & 1 \\
\hline 11 & IFRN & 2019 & Sociologia do Trabalho & 1 \\
\hline 12 & PUC-PR & 2018 & Ética & 1 \\
\hline 13 & UERJ & ND & Engenharia na Sociedade I & 1 \\
\hline 14 & UFAL & 2006 & Ética e Exercício Profissional & 1 \\
\hline 15 & UFAM & 2010 & Sociologia do Trabalho e Ética & 1 \\
\hline 16 & UFCG & 2012 & Introdução à Engenharia Civil & 1 \\
\hline 17 & UFES & 2007 & Introdução À Engenharia Civil & 1 \\
\hline 18 & UFES & 2007 & Aspectos Legais E Éticos Da Engenharia & 1 \\
\hline 19 & UFESSPA & 2017 & Direito e Legislação & 1 \\
\hline 20 & UFG & 2012 & Direito e Legislação & 1 \\
\hline 21 & UFJF & 2017 & Engenharia e Sociedade & 1 \\
\hline 22 & UFMA & 2014 & Legislação Profissional & 1 \\
\hline 23 & UFMS & 2018 & Legislação, Ética Profissional e Cidadania & 1 \\
\hline 24 & UFRB & 2012 & Ética e Sustentabilidade & 1 \\
\hline 25 & UFSM & 2000 & Introdução à Engenharia Civil & 1 \\
\hline 26 & UNIFAP & 2012 & Legislação e Ética & 1 \\
\hline 27 & UNILA & 2019 & Ética e Ciência & 1 \\
\hline 28 & URI & 2014 & Introducão à Engenharia e Ética Profissional & 1 \\
\hline
\end{tabular}

Fonte: Autor

\section{A NECESSIDADE DE UMA NOVA ENGENHARIA CIVIL}

As novas DCN definem em um sentido amplo o que precisa ser feito, mas deixam para as instituições a responsabilidade de definir como reformular os seus currículos, o que - na prática - faz com que o desenvolvimento de um novo Projeto Pedagógico de Curso (PPC) constitua um problema aberto ou "mal definido" nos termos de Rittel e Weber (1984), uma situação de projeto para a qual grande parte dos professores do quadro docente, responsáveis pelas mudanças exigidas pelas novas DCN, não tem preparação, justamente por terem sido formados em currículos que não contemplam o desenvolvimento da competência em concepção de projetos nem uma visão sistêmica.

O currículo atual constitui também uma restrição importante no desafio de inovar na formação dos novos engenheiros, pois há uma tendência no sentido de definir o problema de problema de projeto (a formulação de um novo PPC é um problema de projeto) de modo estreito, muitas vezes a partir da solução atual, o qual, conforme a literatura clássica mostra, limita o espaço de solução (KRICK, 1970; BAZZO e PEREIRA, 2011) e, consequentemente, 
o desenvolvimento de um currículo que propicie o desenvolvimento das habilidades e competências previstas nas novas DCN.

A iniciativa CDIO - Conceive-Design-Implement-Operate (CRAWLEY, 2014) fornece um arcabouço sólido e coerente para a formação dos novos engenheiros, tendo como pano de fundo o ciclo de vida do projeto. Essa perspectiva possibilita o alinhamento do ciclo de vida com o ideal da sustentabilidade e suas dimensões principais - econômica, ambiental e social. Nesse esquema, as competências de Ética e Projeto podem ser incorporadas na formação de engenheiros, pois elas permeiam o currículo do curso, superando as abordagens tradicionais teórico-conceituais através de disciplinas isoladas.

A estrutura pedagógica do CDIO enfatiza o significado do contexto, do conteúdo e dos objetivos e atividades do discente com base no ideal confuciano "Diga-me, e eu esquecerei, mostre-me e eu vou lembrar, envolva-me e eu vou aprender". Assim, o discente tem estruturas ou constructos de conhecimento que podem ser anexados, assimilados e acomodados a novas experiências e conhecimentos, onde a Aprendizagem Experiencial é de grande interesse, pois enfatiza uma abordagem holística do processo de aprendizagem. Assim, como um conjunto de valores, Ética e Projeto podem ser assimilados através de um esquema de desenvolvimento de competências que, partindo do conhecimento (saber), gerem habilidades (saber fazer) que delineiem a atitude ética do profissional - o "saber ser" ético.

Na opinião de Nahra (1999), é recomendável fornecer uma visão que conceitue a ética filosófica e, a seguir, apresente problemas éticos práticos enfrentados pelos engenheiros no desenvolvimento de projetos, explorando opções de solução para esses problemas através da aplicação de princípios da ética filosófica. Nesse sentido, o esquema CDIO fornece os elementos necessários para esse fim através de uma estrutura que estabelece um conjunto de conhecimentos, habilidades e atitudes que conformam o perfil do egresso, além de um modelo do processo de desenvolvimento do currículo integrado.

Considerando que um PPC é o principal balizador do processo formativo, ele deve explicitar como o perfil geral do egresso será construído ao longo do curso. Nesse sentido, um PPC não surge por geração espontânea; é preciso projetar o processo formativo, pois tal processo envolve um conjunto amplo de elementos que têm de ser compatibilizados, além de interesses e condições contextuais das mais variadas que têm que ser reunidas em uma proposta coesa de formação. É por esse motivo que as novas DCN, no seu Art. 6º são enfáticas em colocar o papel do PPC como primordial, porque ele será também o instrumento de avaliação para o acompanhamento do curso.

O PPC deverá evidenciar a coerência entre objetivos do curso, perfil do egresso e matriz curricular, tomando por referência as DCN e as recomendações do ENADE, mostrando claramente como serão desenvolvidas e avaliadas as competências profissionais. Noutras palavras, a matriz curricular tem que ser representativa das competências a serem desenvolvidas para a formação do perfil desejado. Consequentemente, não se trata de qualquer matriz curricular, mas daquela matriz curricular que demonstravelmente permita gerar as competências definidas para a formação do perfil do egresso. Assim, as estratégias e metodologias de ensino precisam estar atreladas às competências a serem desenvolvidas pelo novo PPC, consensuadas a partir da definição de um perfil do egresso.

Êlmor et Al (2019) descrevem um elenco de 12 abordagens que dão suporte ao conceito de Aula Invertida. O Centro para a Inovação Educacional da Universidade de Minnesota apresenta um elenco de 19 abordagens, classificadas de acordo com sua complexidade. Na página do Fórum de Ensino + Aprendizagem da Universidade de Califórnia em San Diego é apresentado um compêndio de 228 estratégias de Aprendizagem ativa (YEE, 2021). 
Neste ponto, importante é destacar que não existe uma metodologia específica passível de ser usada para todo o currículo. A escolha da estratégia, ferramenta ou método dependerá sempre da clara definição de critérios e objetivos em matéria de aprendizagem, dentro de um contexto de competência a ser desenvolvida. Nessa mesma linha, será necessário também definir o papel da tecnologia e como ela se encaixa na abordagem a ser adotada.

Um ator importante em todo esse processo é o professor. E as novas DCN chamam a atenção para a necessidade de uma atuação equilibrada no tripé ensino-pesquisaextensão, o que vem chamar a atenção para a necessidade de valorização do ensino na graduação, o que significa um acordo para que as políticas institucionais incentivem, também, a valorização da docência.

\section{CONSIDERAÇÕES FINAIS}

A Engenharia Civil vivencia uma etapa de mudanças significativas no contexto das novas demandas colocadas pela chamada Indústria 4.0. Os modelos educacionais tradicionais mostram-se esgotados e apontam para a necessidade de se repensar 0 processo formativo dos novos engenheiros, em uma visão não apenas operacional de apresentação de conteúdos e resolução de problemas, mas em uma visão holística, na perspectiva do desenvolvimento de competências profissionais que deem conta apropriadamente das demandas do mundo atual.

Nesse desafio, há uma série de empecilhos a serem vencidos em prol da renovação da Engenharia Civil, a começar pela falta de competência do quadro docente para tratar de um processo de reformulação curricular que, conforme colocado pelas novas DCN, constitui um problema aberto ou "mal definido". Nem mesmo os conselhos profissionais dão conta da complexidade do contexto profissional atual, o que se reflete na falta de atualização quanto às competências entendidas como necessárias para o exercício profissional em um mundo globalizado.

A Falta de uma formação mais ampla dois engenheiros, incorporando competências não técnicas, traz como consequência uma falta de compreensão do seu papel na resolução de problemas da sociedade, o que em grande parte explica os colapsos em obras de construção civil no mais amplo sentido, como são barragens, viadutos ou edifícios, com grande prejuízo em vidas humanas, danos ao meio ambiente e prejuízos financeiros.

A dificuldade em superar esquemas tradicionais de ensino aprendizagem, de caráter disciplinar e o caráter conservador do estamento docente dificultam a abertura de uma discussão sobre PPC e, consequentemente, impedem o desenvolvimento de uma visão estratégica institucional, deixando em aberto algumas questões fundamentais: no final das contas, qual a Engenharia Civil que queremos...? Qual a Engenharia Civil de que o Brasil Precisa...?

\section{REFERÊNCIAS}

ABENGE. Inovação na Educação em Engenharia - proposta de diretrizes para o curso de engenharia: proposta conjunta ABENGE - MEI/CNI. 2018. Disponível em <http://www. abenge. org. br/documentos/PropostaDCNABENGEMEI CNI. pdf>. Acesso em 04, jan, 2021.

ABET - Accreditation Board for Engineering and Technology. Disponível em<https://www. abet. org/>. Acesso em: 04, jan, 2021.

ARAVENA Reyes, José Antonio. Pensar a Formação do Engenheiro para o Antropoceno. 1ํㅡㄹ Encontro Latino-Americano de Engenharia e Sociedade, Anais. São Paulo, 2019. 
Disponível em <https://doity. com. br/anais/engenhariaesociedade/trabalho/88897>. Acesso em: 04, jan, 2021.

ASCE - American Society of Civil Engineering, 2005. Disponível em: <https://www. asce. org/about civil engineering/>. Acesso em: 04, jan, 2021.

BAZZO, Walter Antônio, PEREIRA, Luiz Teixeira do Vale. Introdução à Engenharia. 2. Ed. Florianópolis: Editora da UFSC, 2011.

BRASIL. Lei № 5. 194, de 24 de dezembro de 1966. Disponível em <http://www. planalto. gov. br/ccivil 03/leis/l5194. htm>. Acesso em: 04, jan, 2021.

BRASIL. Lei № 12846, de 1ํ de agosto de 2013. Disponível em <http://www. planalto. gov. br/ccivil 03/ ato2011-2014/2013/lei//12846. htm>. Acesso em 04, jan, 2021.

CAE. Evolution of Engineering Education in Canada. Canadian Academy of Engineering, 1999. Disponível em: <https://cae-acg. ca/wp-content/uploads/2014/01/Eng Issues 8. pdf>. Acesso em: 04, jan, 2021.

CNE/CES. Parecer CNE/CES № 1/2019. 2019a. Disponível em <http://portal. mec. gov. br/docman/marco-2019-pdf/109871-pces001-19-1/file>. Acesso em 04, jan, 2021.

CNE/CES. Resolução CNE/CES № 2/2019. 2019b. Disponível em <http://portal. mec. gov. br/index. php?option=com docman\&view=download\&alias=112681-rces00219\&category slug=abril-2019-pdf\&ltemid=30192>. Acesso em 04, jan, 2021.

CONFEA. Resolução № 1. 048, de 14 de agosto de 2013.

$<$ https://normativos. confea. org. br/ementas/imprimir. asp?idEmenta $=52470>$. Acesso em 04, jan, 2021.

CONFEA. Decisão Normativa № 106, de 17 de abril de 2014, que conceitua o termo "Projeto" e define suas tipificações. Disponível em <http://normativos. confea. org. br/ementas/visualiza. asp?idEmenta=56161>. Acesso em 04, jan, 2021.

CONFEA. Código de Ética Profissional da Engenharia, da Agronomia, da Geologia, da Geografia e da Meteorologia. 11 ${ }^{a}$ Edição | 2019. Disponível em <https://www. confea. org. $\mathrm{br} / \mathrm{sites} /$ default/files/uploads-imce/CodEtica11ed1 com capas no indd. pdf>. Acesso em 04, jan, 2021.

CONTRERAS, José. A autonomia de professores. Tradução: Sandra Trabucco Valenzuela. São Paulo: Cortez, 2002.

CRAWLEY, Edward. F. et Al. Rethinking Engineering Education, 2. Ed. Switzerland: Springer International Publishing, 2014.

ELMÔR Filho, Gabriel et Al. Uma Nova Sala de Aula é Possível - Aprendizagem Ativa

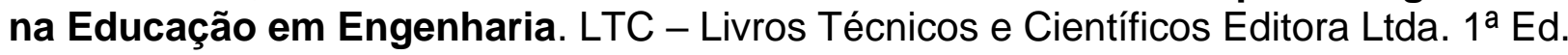
Rio de Janeiro - RJ, 2019. 
Gll. Universidade Cornell. Índice Global de Inovação 2019. 2019. Disponível em <https://www. wipo. int/export/sites/www/pressroom/pt/documents/pr 2019 834. pdf>. Acesso em 04, jan, 2021.

HABASH, Riadh. 2018. Green Engineering: Innovation, Entrepreneurship, and Design. Boca Raton, FL: CRC Taylor and Francis, 2018.

KRICK, Edward V. Introdução à Engenharia. 2a Ed. Rio de Janeiro: Ed. Ao Livro Técnico S.A., 1970.

MEI. Mobilização Empresarial pela Inovação. 2016. Disponível em <https://www. portaldaindustria. com. br/cni/canais/mei/programas-mei/gt-para-o-fortalecimento-daengenharia/>. Acesso em 04, jan, 2021.

NAHRA, Cinara Maria Leite, 1999. Diretrizes Gerais Sobre o Ensino de Ética na Engenharia. In: XXVII Congresso Brasileiro de Ensino na Engenharia. Anais. Natal. 1999. Disponível em <http://www. abenge. org. br/cobenge/arquivos/20/st/s/s013. pdf/>. Acesso em 14, dez, 2019.

OLIVEIRA, Agamenon R.E., 2007. Os desafios atuais para a formação dos engenheiros brasileiros. Cadernos FISENGE 3. Rio de Janeiro: Federação Interestadual de Sindicatos de Engenheiros.

OLIVEIRA, Vanderli Fava de. A Engenharia e as Novas DCNs - Oportunidades para Formar Mais e Melhores Engenheiros. Rio de Janeiro: Ed. LTC - Livros Técnicos e Cientificos Editora Ltda. 2019.

OEP. Código de Ética e Deontologia. Ordem dos Engenheiros de Portugal. 2014. Disponível em <https://www. ordemengenheiros. pt/fotos/editor2/regulamentos/codigo ed. pdf>. Acesso em 04, jan, 2021.

RITTEL, Horst; WEBBER, Melvin. Planning Problems are Wicked Problems. In: CROSS, N. (org), Developments in Design Methodology, John Wiley \& Sons, 1984.

What is Active Learning. Center for Educational Innovation. University of Minnesota. Disponível em <https://cei. umn. edu/active-learning>. Acesso em 04, jan, 2021.

WRIGTH, Paul H. Introduction to Engineering. John Wiley \& Sons. Inc. 2a Ed. Hoboken, NJ. 2002.

YEE, Kevim. InteractiveTechniques. Disponível em <https://commons. ucsd. edu/ files/228-Active-Learning-Strategies. pdf>. Acesso em 04, jan, 2021. 


\title{
ETHICS AND ENGINEERING DESIGN: SOME REFLECTIONS AROUND CIVIL ENGINEERING EDUCATION
}

\begin{abstract}
Population growth demands sustainable solutions in the face of needs such as energy, water, sanitation and infrastructure. On the other hand, the growth of extractive activities with a high environmental risk increases the risk of catastrophes in installations such as barrage, nuclear power plants, viaducts or buildings, with social, environmental and financial costs. This has promoted discussions about the role of engineers and the consequences of their actions. Different normative instruments incorporate the responsibility of engineers through the concept of Professional Ethics - the set of principles or standards that guide professional conduct in the daily practice of engineering. The education of civil engineers involves scientific and technical rigor, but little discussion of social, political or ethical issues. The codes of ethics describe precepts that guide the exercise of the profession, but are silent on the definition of the concept itself or any useful structure for thinking about learning objectives of Ethics and professional responsibility. Ethics has been gaining significant importance in recent years. However, this does not seem to be reflected in the training of future engineers, based on a review of a sample curriculum of Civil Engineering courses in Brazil. While most of them approach Ethics and Engineering Design through isolated disciplines, a few address these subject in a transversal way, through theoretical-conceptual approaches. It is necessary to sensitize future engineers about issues inherent to professional activity through standards of conduct that develop their capacity for judgment in the face of various ethical-moral dilemmas that arise between conflicting objectives, often under great financial or political pressure.
\end{abstract}

Keywords: Ethics, Engineering Design, Teaching, Curriculum. 